\title{
First report of grapevine yellow speckle viroid-1 infecting grapevines in Pakistan
}

\author{
Sunniya Rasool ${ }^{1} \cdot$ Shagufta $\mathrm{Naz}^{2} \cdot$ Madiha Mahmood Gillani $^{2} \cdot$ Adnan Ahmad $^{3}$
}

Received: 5 April 2021 / Accepted: 1 October 2021 / Published online: 15 October 2021

(c) Società Italiana di Patologia Vegetale (S.I.Pa.V.) 2021

Keywords Grapevine $\cdot$ RT-qPCR · GYSVd- 1 HTS

\section{Report}

During 2016, 249 asymptomatic grapevine samples collected from different regions of Pakistan were screened for grapevine viruses and viroid through RT-qPCR (Rasool et al. 2017, 2019). For RT-qPCR results verification, 16 grapevine isolates were analysed by high throughput sequencing (HTS) (Illumina NextSeq 500 platform) of cDNA libraries constructed with TruSeq Stranded Total RNA previous ribosomal RNA depletion. Twelve asymptomatic vines [(AK6 (Sugraan 1), BT26 (Flame Seedless), BT47 (Gilgit), LH3 (Autumn Royal), SW27 (Tarakya Variety), N11 (Alphanso lavallee), N12 (Alphanso), Q4-III (Kishmish), SL13 (Bai-Ji-Xin), SL3 (Venus), SL45 (Zi de qv) and SL53 (Gui fei me gvi)] were positive for grapevine yellow speckle viroid-1 (GYSVd-1). HTS analysis generated approximately 7000, 8500, 2000, 7000, 2500, 800, $100,15,000,7000,7000,3000$ and 3500 reads from the 12 isolates, respectively, were mapped to GYSVd-1 reference genome. The mapped reads from the isolate Q4-III generated a full GYSVd-1 genome of 367 nucleotides (GenBank ID: KY978404) that showed highest identity with the Iranian isolate (KF916042) in database. Results of 12 positive samples were verified by RT-PCR amplification and sequencing by reported primers $341 \mathrm{M}$ (5'-CACTCGCGG GGCGCGTTGGA-3') and 342P (5'-CAATCCCCGGAA
CCCCCGCT-3') that amplified full genome of GYSVd-1 (Sahana et al. 2013). BLASTn analysis revealed 96-100\% identity with GYSVd-1 sequences from GenBank. To best of our knowledge, this is the first report of GYSVd-1 viroid infecting grapevine in Pakistan.

\section{Declarations}

Conflict of interest The authors declare that they have no conflict of interest.

\section{References}

Rasool S, Naz S, Rowhani A, Golino DA, Westrick NM, Farrar KD, Al-Rwahnih M (2017) First report of Grapevine pinot gris virus infecting grapevine in Pakistan. Plant Dis 101:1958-1958

Rasool S, Naz S, Rowhani A, Diaz-Lara A, Golino DA, Farrar KD, Al-Rwahnih M (2019) Survey of grapevine pathogens in Pakistan. J Plant Pathol 101:725-732

Sahana AB, Adkar-Purushothama CR, Chennappa G, Zhang ZX, Sreenivasa MY, Sano T (2013) First report of grapevine yellow speckle viroid-1 and hop stunt viroid infecting grapevines (Vitis vinifera) in India. Plant Dis 97:1517-1517

Publisher's Note Springer Nature remains neutral with regard to jurisdictional claims in published maps and institutional affiliations.

Sunniya Rasool

s.rasool@fjmu.edu.pk

1 Department of Biochemistry, Fatima Jinnah Medical University, Lahore, Pakistan

2 Department of Biotechnology, Lahore College for Women University, Lahore, Pakistan

3 Department of Plant Pathology, The Islamia University of Bahawalpur, Bahawalpur, Pakistan 